\title{
Schechner, teatro e antropologia
}

\author{
John Cowart DaWsey
}

Como o efeito retardado de um ponto luminoso, ou pequena constelação de pontos, num universo de pesquisa descentrado e em expansão, chega o texto de Richard Schechner numa tradução para o português de Ana Letícia de Fiori. Trata-se do ensaio intitulado "Pontos de contato entre o pensamento antropológico e teatral", o primeiro capítulo do livro Between theater and anthropology (1985), um dos marcos dos estudos de performance.

A "virada performativa” (performance turn) nas ciências sociais pode ser pensada a partir de duas vertentes ${ }^{1}$. A primeira, considerada "dramatúrgica”, associa-se a pesquisadores como Victor Turner, Richard Schechner e Erving Goffman. Kenneth Burke, que desenvolveu uma abordagem "dramatista" para análise da vida social, é um de seus precursores. A segunda surgiu como um desdobramento de pesquisas realizadas no campo da linguística, com destaque aos estudos de John Austin. Nesta linhagem - através dos trabalhos de Dell Hymes, Richard Bauman, Charles Briggs e outros pesquisadores - foram elaborados princípios e procedimentos para a realização de etnografias da fala, e estudos de performances narrativas.

Em sua vertente "dramatúrgica”, é de particular interesse para o campo da antropologia a parceria formada por Schechner e Turner ${ }^{2}$. Conforme uma história recorrente, nos anos de 1970, o diretor de teatro experimental Richard Schechner faz a sua aprendizagem na antropologia com Victor Turner, ao mesmo tempo em que Turner, em sua relação com Schechner, torna-se aprendiz de teatro. Desse contato surge um novo campo de estudos, en- tre teatro e antropologia. Dois livros marcam o seu momento originário: From ritual to theatre: the human seriousness of play, de Victor Turner (1982); e Between theater and anthropology, de Richard Schechner (1985). O ensaio "Pontos de contato entre o pensamento antropológico e teatral", traduzido a seguir, é, como dito acima, o primeiro capítulo do livro de Schechner, e aponta para uma série de questóes que se desdobram ao longo do livro.

O ponto de partida de cada um desses autores é diferente. As reflexóes embrionárias de Victor Turner (nascido em 1920) vêm de sua experiência em rituais e dramas sociais Ndembu, nos anos de 1950. As reflexóes mais agudas de Schechner (nascido em 1934), por sua vez, vêm de sua experiência em teatro de vanguarda. De 1967 a 1980, Schechner foi diretor artístico do The Performance Group (TPG) de Nova York, um grupo de teatro experimental que ele mesmo fundou. Em 1992, ele fundou uma nova companhia teatral, East Coast Artists, no qual trabalhou como diretor artístico até $2009^{3}$. Algumas de suas primeiras propostas surgem de experimentos de teatro de rua e protestos contra a Guerra do Vietná.

De acordo com Turner (1985, p. xi), o seu primeiro encontro pessoal com Schechner aconteceu poucas horas antes de uma palestra de Clifford Geertz, em Nova York, em 1977. No mesmo ano, Turner convidou Schechner a participar de uma conferência sobre "Ritual, Drama, e Espetáculo" (Schechner, 2002, p. 11). A seguir, eles juntaram forças para planejar uma "Conferência Mundial sobre Ritual e Performance", que se desdobrou em três con- 
ferências realizadas durante os anos de 1981 e 1982.

Influências mútuas se evidenciam, inclusive antes de 1977. Desdobramentos das discussôes de Turner sobre rituais, dramas sociais, liminaridade e communitas se manifestam em Essays on performance theory (1977), com destaque aos ensaios "From ritual to theater and back: the efficacy-entertainment braid" (publicado originalmente em 1974), e "Selective inattention" (publicado originalmente em 1976). Neste ensaio, Schechner elabora o seu conhecido modelo de um oito deitado, ou símbolo do infinito (infinity-loop model), para discutir as relaçóes interativas entre dramas sociais e dramas estéticos: dramas sociais afetam dramas estéticos, e dramas estéticos afetam dramas sociais.

As influências de Schechner sobre Turner também são marcantes. O próprio infinity-loop model, que Schechner elaborou a partir de suas leituras de Turner, volta a Turner (fazendo um loop) revitalizando suas discussóes. $\mathrm{O}$ modelo sai enriquecido. Particularmente, a noção de "comportamento restaurado" de Schechner foi fundamental para as formulaçóes de Turner. "Aprendi com ele (Schechner)", diz Turner (1985, p. xi), "que toda performance é 'comportamento restaurado', que o fogo do significado irrompe da fricção entre as madeiras duras e suaves do passado [...] e presente da experiência social e individual”. Esta ideia está no cerne da antropologia da experiência elaborada por Turner. A antropologia da performance faz parte de uma antropologia da experiência. De acordo com Turner (1982, p. 14), uma experiência se completa ou realiza através de uma performance, ou forma de expressão.

Durante os cinco anos em que se conheceram (de 1977 até a morte de Turner, em 1982), o antropólogo realizou com Schechner um intenso aprendizado a respeito do teatro experimental que floresceu nos Estados Unidos durante os anos de 1960 e 1970 (cf. Turner, 1982, p. 15). Um dos desdobramentos deste aprendizado foi o livro From ritual to theatre, com destaque ao primeiro capítulo, onde Turner discute um processo de substituição, após a revolução industrial, de gêneros liminares de ação simbólica por formas liminoides.

Turner (1986, p. 42) descreve esse processo como um desmembramento, ou sparagmos, das formas de ação simbólica”. A noção do liminoide é retomada por Schechner, mas sem uma metanarrativa da tragédia. Em Schechner a experiência liminoide - que não deixa de ser descrita, às vezes, com uma ponta de ironia - revela-se em suas dimensóes lúdicas e subversivas.

Dirigindo peças e escrevendo livros, num campo que se configura entre o teatro e a antropologia, Richard Schechner - um "judeu hindu budista ateu morando em New York City", como ele mesmo se apresenta (Schechner, 2002, p. 1) - tornou-se uma das principais referências para estudos de performance. Além de ter sido, como visto, o fundador do The Performance Group (TPG) e do East Coast Artists, ele também fundou a revista TDR: The Journal of Performance Studies, e suas versões anteriores (The Tulane Drama Review, e TDR: The Drama Review). Em 1980, ele foi um dos fundadores do departamento de Performance Studies da Tisch School of the Arts, New York University.

O ensaio traduzido nesta coletânea certamente ilumina alguns dos pontos de contato principais entre o pensamento antropológico e teatral. Porém, aqui proponho um breve exercício inverso: como esses pontos de contato abrem perspectivas para discutir o próprio ensaio de Schechner? Nada nos impede, diz Schechner (2002, p. 24, 32, 110) de considerar qualquer ação humana, ou produto dessa ação, a partir do enquadramento, ou frame, da performance. A seguir, no modo subjuntivo, considerando o ensaio de Schechner como uma 
espécie de performance, algumas notas sobre cada um dos pontos de contato.

\section{Transformação do ser e da consciência}

Os momentos mais eletrizantes de uma performance, em qualquer tradição, podem ser justamente aqueles em que o corpo lampeja por detrás (ou por baixo, acima, et cetera) da máscara. Trata-se, da experiência de quem se descobre como "não-eu" e "não não-eu" ao mesmo tempo. Nesse registro, o próprio ensaio de Schechner, enquanto experimento liminar entre teatro e antropologia, se ilumina. Em cena: um corpo de diretor de teatro, uma máscara de antropólogo. (Ou seria o inverso?).

\section{Intensidade da performance}

Coisas boas para fazer pensar. O que seriam os pontos de contato senão um campo de energia? Com estímulos e inervaçóes corporais é produzido um campo de investigaçôes. Diferentes estéticas, modos variados de produzir intensidade - até mesmo num texto escrito. Seis pontos de contato. Cada ponto pode ser lido de forma independente, e de acordo com diferentes sequências. Tal estética pode propiciar arranjos variados e criativos. Há seis pontos, seis interrupçóes. $\mathrm{O}$ inacabamento do texto nos convida a pensar em possíveis variantes, e pontos alternativos.

\section{Interaçóes entre performers e audiências}

Eis uma questão: a especificidade de audiências e performers, e as relaçôes entre eles. A audiência é constitutiva do evento performático. Quem são os diferentes leitores de
Schechner - do teatro à antropologia? Até que ponto eles se constituem como audiências? $\mathrm{Ou}$ performers? Que espécie de teatro busca Schechner? Um teatro em que o público seja subvertido, tornando-se performer também. Daí o interesse de Schechner por rituais. Um detalhe: esse interesse também tem a ver com uma espécie de envolvimento distraído, ou "inatenção seletiva”. Em tal estado as atençóes das pessoas tornam-se errantes e receptivas a eventos e imagens que poderiam, de outra forma, passar despercebidos.

\section{Sequência total da performance}

Schechner propõe uma sequência total da performance, em sete momentos: a) treinamento, b) oficinas, c) ensaios, d) aquecimentos, e) performance, f) esfriamento, e g) desdobramentos. Como situar o texto de Schechner, num frame da performance? Seria ele um "desdobramento", como o autor sugere? $\mathrm{Ou}$, um ensaio? Esta possibilidade me parece ser especialmente interessante na medida em que a tradução do inglês (rehearsal) para o português (ensaio) permite a junção de um gênero literário (essay) com outro teatral (rehearsal). Nos ensaios, particularmente, experimenta-se ou brinca-se com as múltiplas possibilidades da performance (Schechner, 1985, p. 101, 103, 110, 113).

\section{Transmissão de conhecimento performático}

Considerando a importância das tradiçôes orais para a transmissão do conhecimento performático, como ler o próprio texto de Schechner? Será o caso de ouví-lo, como faria uma audiência? Considerando, ainda, o modo como diferentes sentidos do corpo se mobili- 
zam na significação do mundo, será o caso de se fazer uma leitura corporal do texto envolvendo pontos de vista, pontos de escuta, pontos de cheiro, pontos de sabor, e - de volta ao título - "pontos de contato"?! Ou seriam pontos de contágio? $\mathrm{Ou}$, ainda, pontos de contágio e semelhança? A discussão de Schechner sobre as escrituras em cavernas paleolíticas são interessantes nesse sentido. Em brincadeiras de criança revela-se o "dom de tornar-se semelhante" (cf. Benjamin, 1985). Voltamos ao primeiro ponto: a experiência liminar de quem se descobre como "não-eu" e "não não-eu" ao mesmo tempo.

\section{Como performances sáo geradas e avaliadas?}

Chama atenção o ponto de interrogação. Acumulam-se questóes. A ideia de Schechner de articular a crítica da performance ao processo de ensaio é particularmente interessante. Como fazer uma avaliação no registro do ensaio, ou da subjuntividade? Como despertar na performance possibilidades que ainda não vieram a ser? $\mathrm{E}$, como avaliar o próprio texto de Schechner? A questão, quem sabe, pode nos conduzir a alguns de seus lugares preferidos, o espaço de um ensaio, ou chão de uma oficina.

\section{Conclusão}

Que espécie de conclusão é essa? Abrem-se novas questóes. Em alguns de seus escritos, Victor Turner (cf. 1982, p. 13-14) discute a noção de performance tendo em mente a sua derivação do francês antigo parfournir, "completar" ou "realizar inteiramente". A performance completa uma experiência. Porém, o que se entende por completar? Essencial à performance - e, aqui, recorremos a Turner e
Schechner - é a sua abertura. Enfim, uma conclusão que se abre.

\section{Notas}

1. A "virada performativa", que ocorre em um conjunto amplo e variado de disciplinas, envolve uma mudança paradigmática. Questionando o texto-centrismo e a primazia das análises de estruturas sociais e simbólicas em diversos campos, pesquisadores voltam suas atenções também para a ação humana e para o modo como os sentidos do corpo são mobilizados na significação do mundo.

2. A produção bibliográfica de Richard Schechner e Victor Turner é expressiva. A seguir, os livros de Schechner: Public domain (1968); Environmental theater (1973); Theaters, spaces, and environments (1975, com Jerry Rojo e Brooks McNamara); Essays on performance theory (1976); The end of humanism (1981); From the Ramlila to the avantgarde (1983); Between theater and anthropology (1985); The Engleburt stories (1987, com Samuel McIntosh Schechner); The future of ritual (1993); Performance theory (edição revista de Esssays on performance theory, 1988; nova revisão em 2004); Performance studies - an introduction (2002, segunda edição revista em 2006); Over, under, and around (2004). Schechner também organizou várias coletâneas: Dionysus in 69 (1970); Ritual, play, and performance (1976, com Mady Schuman); By means of performance (1990, com Willa Appel); e The Grotowski sourcebook (1997, com Lisa Wolford).

A obra de Turner inclui os seguintes livros: Schism and continuity in an African society: a study of Ndembu village life (1957); The forest of symbols: aspects of Ndembu ritual (1967); The drums of affliction (1968); The ritual process: structure and anti-structure (1969); Dramas, fields and metaphors: symbolic action in human society (1974); Revelation and divination in Ndembu ritual (1975); From ritual to theatre: the human seriousness of play (1982); On the edge of the bush (1985, obra póstuma); e The anthropology of performance (1987, obra póstuma). Victor Turner também aparece como o organizador de várias coletâneas: Image and pilgrimage in Christian culture (1978, com Edith Turner) Celebration: studies in festivity and ritual (1982); e The anthro- 